\title{
Yetişkin Bireylerin Sağlık Okuryazarlığı ve Obeziteyle İlişkili Bazı Davranışlarının İncelenmesi
}

\author{
Investigation of Health Literacy and Some Behavior Related \\ with Obesity in Adult Individuals \\ Pınar Soylar ${ }^{1}$, Bircan Ulaş Kadığlu ${ }^{2}$ \\ ${ }^{1}$ Fırat Üniversitesi, Sağlık Bilimleri Fakültesi, Hemşirelik Bölümü, Elazı̆̆ \\ ${ }^{2}$ Osmaniye Korkut Ata Üniversitesi, Sağlık Bilimleri Fakültesi, Beslenme ve Diyetetik Bölümü, Osmaniye \\ Yazıșma Adresi / Correspondence: \\ Pinar Soylar \\ Firat Üniversitesi, Sağılk Bilimleri Fakültesi, 23119, Elazı̆̆ \\ T: +90 424237000 / 8297 E-mail : psoylar@gmail.com \\ Geliş Tarihi / Received : 09.03.2020 Kabul Tarihi / Accepted : 27.05.2020 \\ Orcid : \\ Pinar Soylar: https://orcid.org/0000-0003-1565-2100 \\ Bircan Ulaş Kadığlu: https://orcid.org/0000-0002-1150-8761 \\ (Sakarya Tip Dergisi / Sakarya Med J 2020, 10(2):270-276) DOI: 10.31832 smj.700979
}

\footnotetext{
$\ddot{O ̈ z}_{2}$

Amaç Sağılğın geliştirilmesinde sağlık okuryazarlı̆̆ının rolü önemlidir. Yetişkin bireylerin sağlık okuryazarlığı̆ düzeyinin saptanması ve obeziteyle ilişkili bazı davranışların sağık okuryazarlığına etkisinin incelenmesi amaçlanmıștır.

Gereç ve Tanımlayıcı türde kesitsel bir çalıșma olan araștırmamız, Elazığ il merkezindeki üç aile sağlığı merkezine bașvuran ve araștırmamıza katılmayı kabul eden 680 yetişkin birey

Yöntem ile Kasım-Aralık 2019 tarihleri arasında yürütülmüştür. Veri toplama aracı olarak sosyo demografik sorular ile birlikte obeziteyle ilişkili olduğu düşünülen değişkenler, ve "Türkiye Sağlık Okuryazarlı̆̆ı Ölçeği-32 (TSOY-32)" kullanılmıştır.

Bulgular Katılımcların \%46,8’i fazla kilolu, \%37,9’u obezdi. \%39,0’unun sağlık okuryazarlığı yetersiz, \%32,5’unun sınırlı, \%17,8’i yeterli, \%10,7’si mükemmel düzeyde idi. Bireylerin beden kitle indeksleri ile sağlı okuryazarlığı arasında anlamlı bir ilișki bulunmuş olup ( $\mathrm{p}=0,018$ ), düzenli egzersiz yapma durumu, sebze-meyve tüketimi ve düzenli beslenmenin sağlık okuryazarlığı ile arasında anlamlı bir ilişki saptanmıştır ( $\mathrm{p}=0,016, \mathrm{p}=0,010, \mathrm{p}=0,008$ sırasıyla).

Sonuç Katılımcıların büyük çoğunluğunun sağlık okuryazarlığı yetersiz olarak bulunmuştur. Yetersiz seviyede sağlık okuryazarlığının vücut artışı ile ilișkili olduğu sonucuna varılmıştır. Toplumun sağlık okuryazarlığı konusunda farkındalığının artması sağlıklı yaşam davranışlarının kazanılmasında ve kilo kontrolünde etkili olabilir.

Anahtar Sağllk Okuryazarlığı; beden kitle indeksi; obezite; sağlığın geliştirilmesi.

Kelimeler

Abstract

Objective The role of health literacy in health promotion is important. It was aimed to determine the level of health literacy of adults and to examine the effects of some obesity-related behaviors on health literacy.

Materials Our research, a descriptive cross-sectional study, conducted between November and December, 2019, included a total of 680 participants, who applied to the primary care unit. The particiand methods pants were investigated for their demographic variables and some questions that are thought to be related to obesity. Also Turkish Health Literacy Scale-32 (THLS-32) was used to determine their health literacy level.

Results $\quad 46,8 \%$ of the participants was overweight, $37,9 \%$ of them was obesity. 39,0\% of the individuals had insufficient helath literacy, 32,5\% of them were limited, $17,8 \%$ of them were sufficient and $10,7 \%$ of them were excellent. There was a significant relationship was determined between body mass index and health literacy level ( $p=0,018)$, and also there was a statistically significant relationship between regular exercise and nutrition, consumption of fruit and vegetables and health literacy level $(p=0,016, p=0,010, p=0,008$ respectively).

Conclusion The majority of the participants had insufficient health literacy level. It was concluded that inadequate health literacy was associated with increased body weight. Increasing awareness of the society about health literacy can be effective in gaining healthy lifestyle behaviors and weight control.

Keywords Helath literacy; body mass indeks; obesity; health promotion
} 


\section{GIIRIŞ}

Ülkemizde ve dünyada her geçen gün bulaşıcı olmayan hastalıkların prevalansının artması koruyucu sağlık hizmetlerine daha fazla önem verilmesini gerekli kılmaktadır. Koruyucu sağlık hizmetleri için önemli olan sağlıklı yaşam alışkanlıklarının kazanılmasında ise sağlık okuryazarlığının rolü büyüktür. ${ }^{1}$ Dünya Sağlık Örgütüne göre sağlık okuryazarlığı, sağlığı geliştirecek bilgileri kullanma ve anlamanın yanı sıra bireylerin sağlık hizmetlerine ulaşmasını etkileyen hem bilişsel hem de sosyal becerilerini tanımlamaktadır. ${ }^{2}$ Sağlık okuryazarlığı sağlıkta eşitsizlikleri azaltır, bireylerin kendi sağlıkları üzerindeki kontrollerini artırır. $^{3,4}$

Yetersiz sağlık okuryazarlığı, yüksek oranda hastaneye başvuru, acil servislerin aşırı kullanımı, tedaviye uyumsuzluk, kronik hastalıkların görülme sıklığının artması gibi kötü sağlık sonuçları ile ilişkilidir. ${ }^{5,6,7}$ Kronik hastalığı olan ve yetersiz sağlık okuryazarlığı olan hastalar, kronik hastalığı olan ve yeterli sağlık okuryazarlığı olan hastalara göre doktorlarının talimatlarını daha fazla yanlış anladıkları tespit edilmiştir. ${ }^{8}$ Bireylerin sağlık okuryazarlığının yüksek olması sağlığı geliştiren davranışları benimsemelerini sağlar, koruyucu sağlık hizmetlerine katılmalarını artırır ve bula\$̧ıcı olmayan hastalıkların prevalansını düşürür., ${ }^{9,10,11,12}$ Sağlık okuryazarlığı yüksek seviyede olan bireylerin yaşamları boyunca daha sağlıklı seçimler yaptığı, sağlıklı beslenme konusunda daha dikkatli davrandıkları belirtilmiştir. Yapılan çalışmalar yeterli seviyede sağlık okuryazarlığı olan bireylerin daha az şeker içeren gıdaları tercih ettiğini, daha fazla sebze-meyve tükettiğini göstermiştir. ${ }^{13}$ Düşük seviyede sağlık okuryazarlığı olan bireyler, obezitenin yol açtığı sağlık problemleri konusunda daha az bilgiye sahip iken ideal kilonun korunmasında ise daha az çaba gösterdikleri belirlenmiştir. ${ }^{14}$

Ülkemizde yetişkinlerin sağlık okuryazarlığı düzeyi \%6 ile \%72.9 arasında değişmekte olup bazı çalışmalarda sağlık okuryazarlığının yetersiz seviyede olduğu belirtilmiştir. 1,10,15,16 Literatürdeki bazı çalışmalar yeterli sağlık okurya- zarlığı düzeyine sahip bireylerin düzenli fiziksel aktivite, sağlıklı yeme alışkanlıkları gibi sağlığı geliştiren davranışları daha fazla benimsediklerini göstermektedir. ${ }^{17,18,19}$

Çok az sayıda çalışma obeziteyle ilişkili faktörler ile sağlık okuryazarlığını karşılaştırmıştır. Mevcut araştırmalara göre ülkemizde bu konuda yapılmış çalışmaya rastlanmamıştır. Bu çalışmada yetişkin bireylerin sağlık okuryazarlığı düzeyinin saptanması ve obeziteyle ilişkili bazı davranışların etkisinin incelenmesi amaçlanmıştır.

\section{GEREÇ ve YÖNTEM}

Tanımlayıcı türde kesitsel bir çalışma olan araştırmamız, Elazığ il merkezindeki üç aile sağlı̆̆ı merkezinde (Cumhuriyet, İzzetpaşa ve Yenimahalle) yürütülmüştür. Araştırmacılar, il sağlık müdürlüğünden alınan kurum izni doğrultusunda ve yine müdürlük tarafından belirlenen aile hekimliklerine gidebilmiştir. Araştırmamız Kasım-Aralık 2019 tarihleri arasında aile sağlığı merkezine başvuran ve araştırmamıza katılmayı kabul eden yetişkin bireyler ile yürütülmüştür. Herhangi bir ruhsal bozukluğu olan, iletişim problemi olan, 18 yaş altındaki bireyler ile beden kitle indeksi zayıf olanlar çalışmaya dahil edilmemiştir.

Literatürden yararlanarak, kadın ve erkelerdeki sağlık okuryazarlığı ortalama puanı baz alınmış olup \%95 güven aralığında, \%80 güç ile etki büyüklügü 0,2 olarak hesaplanmıştır. ${ }^{11}$ Örneklem sayısı, power analiz sonucunda 313 erkek 313 kadın olmak üzere toplam 626 birey olarak belirlenmiştir. Olabilecek veri kaybını önlemek adına 700 kişiye anket yapılmış olup eksik doldurulan anketlerin çıkarılmasından sonra araştırmamız 680 birey ile tamamlanmiştır.

Veri toplama aracı olarak sosyo demografik sorular (10 soru) ile birlikte obeziteyle ilişkili olduğu düşünülen değişkenler (5 soru) ve "Türkiye Sağlık Okuryazarlığı Ölçeği-32 (TSOY-32)” kullanılmıştır. Bireylerin obezite ile ilişkili davranışlarını değerlendirmek üzere hazırlanan sorular literatürden yararlanarak düzenlenmiştir. ${ }^{17,18,19}$ Düzenli 
olarak haftada en az $150 \mathrm{dk}$ orta derecede herhangi bir fiziksel aktivite yapanlar düzenli egzersiz yapıyor (haftanın en az 5 günü ve günde en az $30 \mathrm{dk}$ olacak şekilde bahçe işleri, ev işleri, tempolu yürüyüş, bisiklet vb); bir günde 3 öğün yemek yiyenler düzenli besleniyor şeklinde değerlendirilmiştir. Avrupa Sağlık Okuryazarlığı Konsorsiyumu (HLS-EU CONSERTIUM) tarafından geliştirilen ölçeğin kavramsal çerçevesi temel alınarak Okyay ve arkadaşları tarafından Türkçe güvenilirlik ve geçerliliği yapılmıştır. En düşük 0, en yüksek 50 puan alınan TSOY-32 ölçeğinde 32 soru yer almaktadır. ${ }^{15}$ Ölçekten alınan puanlar

- $\quad$ 0-25 puan: yetersiz sağlık okuryazarlığı,

- $\quad$ 25-33 puan: sorunlu-sınırlı sağlık okuryazarlığı

- $\quad$ 33-42 puan: yeterli sağlık okuryazarlığı

- $\quad$ 42-50 puan: mükemmel sağlık okuryazarlığı olarak dört kategoride sınıflandırılmıştır.

Boy ve kilo ölçümleri araştırmacılar tarafından yapılarak beden kitle indeksleri BKİ=A ğırlık $(\mathrm{kg}) / \operatorname{Boy}(\mathrm{m} 2)$ formülü ile hesaplanmıştır. Beden Kitle İndeksleri (BKİ) Dünya Sağlık Örgütü sınıflandırma sistemi kullanılarak 18.5-24.9 arası normal kilolu, 25-29.9 arası hafif kilolu; 30-39.9 arası obez şeklinde uc grupta incelenmiştir. ${ }^{20}$

Araştırmamızdan elde edilen verilerin analizi SPSS 22.0 programı ile yapılmıştır. Kategorik veriler frekans ve yüzdeler olarak verilmiştir. Verilerin istatistiksel analizinde Pearson's $\chi 2$ testi kullanılmıştır. Veriler değerlendirilirken $\% 95$ güven aralığında ve $\mathrm{p}<0.05$ istatistiksel olarak anlamlı kabul edilmiştir.

Fırat Üniversitesi Sosyal ve Beşeri Bilimler Araştırmaları Etik Kurulunun 17.10.2019 tarih ve 36/12 Nolu etik kurul kararı ile araştırmamız için izin alınmıştır.

\section{BULGULAR}

Araştırmamıza katılan bireylerin yaş ortalaması

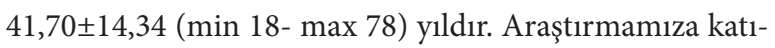
lanların \%69,4'ü kadın, \%72,9'u evli, \%52,2'si lise ve üzeri eğitim seviyesine sahiptir. Katılımcıların \%46,8'i fazla ki- lolu, \%37,9'u obezdi. \%39,0 unun sağlık okuryazarlığı yetersiz, \%32,5'unun sinırlı, \%17,8'i yeterli, \%10,7'si mükemmel düzeyde idi. \%67,1’i düzenli egzersiz yapmadığını, \% 45,3’u her gün sebze-meyve tükettiğini, \%52,2'si düzenli olarak (üç öğün yemek) beslendiğini belirtmiştir (Tablo 1).

\begin{tabular}{|c|c|c|}
\hline Değișkenler & $\mathbf{n}$ & $\%$ \\
\hline \multicolumn{3}{|l|}{ Cinsiyet } \\
\hline Kadın & 472 & 69,4 \\
\hline Erkek & 208 & 30,6 \\
\hline \multicolumn{3}{|l|}{ Yaș } \\
\hline $15-35$ yaş & 225 & 33,1 \\
\hline $36-50$ yaş & 274 & 40,3 \\
\hline $51-78$ yaş & 181 & 26,6 \\
\hline \multicolumn{3}{|l|}{ Medeni Durum } \\
\hline Evli & 496 & 72,9 \\
\hline Bekar & 184 & 27,1 \\
\hline \multicolumn{3}{|l|}{ Eğitim } \\
\hline İlköğretim & 325 & 47,8 \\
\hline Lise ve üzeri & 355 & 52,2 \\
\hline \multicolumn{3}{|l|}{ Meslek } \\
\hline Çalışıyor & 314 & 46,2 \\
\hline Çalışmıyor & 366 & 53,8 \\
\hline \multicolumn{3}{|l|}{ BKİ } \\
\hline Normal & 104 & 15,3 \\
\hline Hafif kilolu & 318 & 46,8 \\
\hline Obez & 258 & 37,9 \\
\hline \multicolumn{3}{|c|}{ Sağlık Okuryazarlığı } \\
\hline Yetersiz & 265 & 39,0 \\
\hline Sinırlı & 221 & 32,5 \\
\hline Yeterli & 121 & 17,8 \\
\hline Mükemmel & 73 & 10,7 \\
\hline \multicolumn{3}{|c|}{ Düzenli Egzersiz ${ }^{\star *}$} \\
\hline Evet & 224 & 32,9 \\
\hline Hayır & 456 & 67,1 \\
\hline \multicolumn{3}{|c|}{ Sebze Meyve Tüketimi } \\
\hline Her gün & 308 & 45,3 \\
\hline Bazen & 372 & 54,7 \\
\hline \multicolumn{3}{|c|}{ Düzenli Beslenme* } \\
\hline Evet & 355 & 52,2 \\
\hline Hayır & 325 & 47,8 \\
\hline \multicolumn{3}{|c|}{$\begin{array}{l}\text { *Günde } 3 \text { ögün beslenenler 'düzenli beslenenler' olarak değerlendirilmiştir. }{ }^{* *} \text { Düzenli } \\
\text { olarak haftada en az } 150 \mathrm{dk} \text { orta derecede herhangi bir fiziksel aktivite yapanlar 'düzenli } \\
\text { egzersiz’ yapyyor șeklinde değerlendirilmiștir. BKİ: Beden Kitle İndeksi }\end{array}$} \\
\hline
\end{tabular}


Katılımcıların, obeziteyle ilişkili değişkenlerinin BKİleri ile karşılaştırılması Tablo 2'de verilmiştir. Düzenli egzersiz yapma durumu, sebze-meyve tüketimi ve düzenli beslen- menin BKİleri ile arasında anlamlı bir ilişki saptanmamış$\operatorname{tir}(\mathrm{p}>0,05)$.

\begin{tabular}{|c|c|c|c|c|c|c|c|c|c|}
\hline \multirow{2}{*}{ Değişkenler } & \multicolumn{2}{|c|}{ Normal } & \multicolumn{2}{|c|}{ BKİ Hafif Kilolu } & \multicolumn{2}{|c|}{ Obez } & \multicolumn{2}{|c|}{ Toplam } & \multirow{2}{*}{$\mathbf{p}$} \\
\hline & $\mathrm{n}$ & $\%$ & $\mathrm{n}$ & $\%$ & $\mathrm{n}$ & $\%$ & $\mathrm{n}$ & $\%^{* * *}$ & \\
\hline \multicolumn{10}{|c|}{ Düzenli Egzersiz $^{\star *}$} \\
\hline Evet & 33 & 14,7 & 111 & 49,6 & 80 & 35,7 & 224 & 32,9 & \multirow{3}{*}{0,588} \\
\hline \multirow[t]{2}{*}{ Hayır } & 71 & 15,6 & 207 & 45,4 & 178 & 39,0 & 456 & 67,1 & \\
\hline & & & & & & & 680 & 100,0 & \\
\hline \multicolumn{10}{|c|}{ Sebze Meyve Tüketimi } \\
\hline Her gün & 44 & 14,3 & 147 & 47,7 & 117 & 38,0 & 308 & 45,3 & \multirow{3}{*}{0,784} \\
\hline \multirow[t]{2}{*}{ Bazen } & 60 & 16,1 & 171 & 46,0 & 141 & 37,9 & 372 & 54,7 & \\
\hline & & & & & & & 680 & 100,0 & \\
\hline \multicolumn{10}{|c|}{ Düzenli Beslenme $^{*}$} \\
\hline Evet & 48 & 13,5 & 167 & 47,0 & 140 & 39,4 & 355 & 52,2 & \multirow{3}{*}{0,372} \\
\hline \multirow[t]{2}{*}{ Hayır } & 56 & 17,2 & 151 & 46,5 & 118 & 36,3 & 325 & 47,8 & \\
\hline & & & & & & & 680 & 100,0 & \\
\hline
\end{tabular}

Katılımcıların bazı sosyodemografik ve obeziteyle ilişkili değişkenlerinin sağlık okuryazarlığı puanlarına göre dağ lımı Tablo 3’te verilmiştir. Sağlık okuryazarlığ 1 puanlarının cinsiyet $(\mathrm{p}=0,326)$ ve yaş grupları $(\mathrm{p}=0,270)$ ile arasında anlamlı bir ilişki bulunmazken eğitim düzeyi yükseldikçe sağlık okuryazarlığı puanlarının arttığı görülmüştür $(\mathrm{p}=0,008)$. Bireylerin BKİleri ile sağlık okuryazarlığ 1 arasında anlamlı bir ilişki bulunmuş olup $(\mathrm{p}=0,018)$, sağlık okuryazarlığı yetersiz düzeyde olanların çoğunluğu hafif kilolu ve obez bireylerden oluşmaktaydı. Düzenli egzersiz yapma durumu, sebze-meyve tüketimi ve düzenli beslenmenin sağlık okuryazarlığı ile arasında anlamlı bir ilişki saptanmıştır $(\mathrm{p}<0,05)$. 
Sakarya Tip Dergisi 2020;10(2):270-276

SOYLAR ve Ark., Sağlık Okuryazarlığı ve Obezite

\begin{tabular}{|c|c|c|c|c|c|c|c|c|c|c|c|}
\hline \multirow{3}{*}{ Değişkenler } & \multicolumn{10}{|c|}{ SAĞLIK OKURYAZARLIĞI } & \multirow{3}{*}{$\mathrm{p}$} \\
\hline & \multicolumn{2}{|c|}{ Yetersiz } & \multicolumn{2}{|c|}{ Sinurlı } & \multicolumn{2}{|c|}{ Yeterli } & \multicolumn{2}{|c|}{ Mükemmel } & \multicolumn{2}{|c|}{ Toplam } & \\
\hline & $\mathrm{n}$ & $\%$ & $\mathrm{n}$ & $\%$ & $\mathrm{n}$ & $\%$ & $\mathrm{n}$ & $\%$ & $\mathrm{n}$ & $\%^{* * *}$ & \\
\hline \multicolumn{12}{|l|}{ Cinsiyet } \\
\hline Kadın & 189 & 40,0 & 148 & 31,4 & 89 & 18,9 & 46 & 9,7 & 472 & 69,4 & \multirow{3}{*}{0,326} \\
\hline \multirow[t]{2}{*}{ Erkek } & 76 & 36,5 & 73 & 35,1 & 32 & 15,4 & 27 & 13,0 & 208 & 30,6 & \\
\hline & & & & & & & & & 680 & 100,0 & \\
\hline \multicolumn{12}{|l|}{ Yaș } \\
\hline $15-35$ yaş & 87 & 38,7 & 68 & 30,2 & 39 & 17,3 & 31 & 13,8 & 225 & 33,1 & \multirow{4}{*}{0,270} \\
\hline $36-50$ yaş & 104 & 38,0 & 86 & 31,4 & 55 & 20,1 & 29 & 10,6 & 274 & 40,3 & \\
\hline \multirow[t]{2}{*}{ 51-78 yaş } & 74 & 40,9 & 67 & 37,0 & 27 & 14,9 & 13 & 7,2 & 181 & 26,6 & \\
\hline & & & & & & & & & 680 & 100,0 & \\
\hline \multicolumn{12}{|l|}{ Eğitim } \\
\hline İlköğretim & 132 & 40,6 & 111 & 34,2 & 61 & 18,8 & 21 & 6,5 & 325 & 47,8 & \multirow{3}{*}{0,008} \\
\hline \multirow[t]{2}{*}{ Lise ve üzeri } & 133 & 37,5 & 110 & 31,0 & 60 & 16,9 & 52 & 14 & 355 & 52,2 & \\
\hline & & & & & & & & & 680 & 100,0 & \\
\hline \multicolumn{12}{|l|}{ BKI } \\
\hline Normal & 24 & 23,1 & 45 & 43,3 & 22 & 21,2 & 13 & 12,5 & 104 & 15,3 & \multirow{4}{*}{0,018} \\
\hline Hafif kilolu & 138 & 43,4 & 99 & 31,1 & 49 & 15,4 & 32 & 10,1 & 318 & 46,8 & \\
\hline \multirow[t]{2}{*}{ Obez } & 103 & 39,9 & 77 & 29,8 & 50 & 19,4 & 28 & 10,9 & 258 & 37,9 & \\
\hline & & & & & & & & & 680 & 100,0 & \\
\hline \multicolumn{12}{|c|}{ Düzenli Egzersiz ${ }^{* *}$} \\
\hline Evet & 74 & 33,0 & 54 & 24,1 & 57 & 25,4 & 39 & 17,4 & 224 & 32,9 & \multirow{3}{*}{0,016} \\
\hline \multirow[t]{2}{*}{ Hayır } & 191 & 41,9 & 167 & 36,6 & 64 & 14,0 & 34 & 7,5 & 456 & 67,1 & \\
\hline & & & & & & & & & 680 & 100,0 & \\
\hline \multicolumn{12}{|c|}{ Sebze Meyve Tüketimi } \\
\hline Her gün & 102 & 33,1 & 69 & 22,4 & 81 & 26,3 & 56 & 18,2 & 308 & 45,3 & \multirow{3}{*}{0,010} \\
\hline \multirow[t]{2}{*}{ Bazen } & 163 & 43,8 & 152 & 40,9 & 40 & 10,8 & 17 & 4,6 & 372 & 54,7 & \\
\hline & & & & & & & & & 680 & 100,0 & \\
\hline Düzenli Besle & & & & & & & & & & & \\
\hline Evet & 100 & 28,2 & 111 & 31,3 & 99 & 27,9 & 45 & 12,7 & 355 & 52,2 & \\
\hline Hayır & 165 & 50,8 & 110 & 33,8 & 22 & 6,8 & 28 & 8,6 & 325 & 47,8 & 0,008 \\
\hline & & & & & & & & & 680 & 100,0 & \\
\hline $\begin{array}{l}\text { Ki kare analizi } \\
{ }^{*} \text { Günde } 3 \text { öğür }\end{array}$ & $\mathrm{m} 1 s$ & 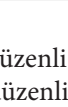 & 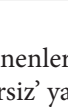 & 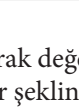 & & & & 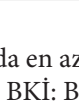 & & 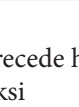 & angi \\
\hline
\end{tabular}




\section{TARTIŞMA}

Çalışmamıza katılan 680 bireyin sağlık okuryazarlığı düzeyi literatür doğrultusunda iki grupta sınıflandırılarak tartışılmıştır (yetersiz ve sınırlı olanlar 'yetersiz'; yeterli ve mükemmel olanlar ise 'yeterli'). Bireylerin \%71,4'ünün sağlık okuryazarlığı düzeyi yetersiz, \%28,6'sının yeterli olduğu saptanmıştır. İran'da yapılan bir çalışmada katılımc1ların \%58'inin sağlık okuryazarlığı düzeyi yetersiz bulunmuş, diyabet hastaları ile yürütülen başka bir çalışmada ise hastaların \% 70'inin sağlık okuryazarlığı düzeyi yetersiz bulunmuştur. ${ }^{21,22}$ Çin'de yaşlı bireyler ile yürütülen bir çalışmada katılımcıların sağlık okuryazarlığı düzeyi yine düşük olarak tespit edilmişsir. ${ }^{23}$ Araştırmamızdan elde edilen sonuçların literatür ile uyumlu olduğu görülmektedir.

Erkek ve eğitim düzeyi yüksek bireyler ile gençlerin sağlık okuryazarlığı; kadın, eğitim düzeyi düşük ve yaşlı bireylere göre daha yüksek olduğu yapılan çalışmalarda gösterilmiştir. ${ }^{22,24}$ Araştırmamızda sadece eğitim düzeyi yüksek bireylerde sağlık okuryazarlığı düzeyi yüksek bulunmuştur.

Araştırmamıza dahil edilen bireylerin sağlık okuryazarlığ yetersiz olanların çoğunluğu hafif kilolu ve obez grubunda yer almaktaydı. Sağlık okuryazarlığı ile vücut ağılı̆̆̆ arasındaki ilişkiyi inceleyen çalışmalarda araştırmamızla benzer şekilde düşük sağlık okuryazarlığı ile artmış BKİ arasında ilişki olduğu belirtilmiştir. 25,26,27 Düşük sağlık okuryazarlığı ve artmış vücut ağırlığı konusunda yap1lan bir sistematik derlemede sağlık okuryazarlığ arasındaki ilişkinin negatif yönde anlamlı olduğu, sağlık okuryazarlığı düzeyi arttıkça BKİ’nin azaldığı sonucuna varılmıştır. ${ }^{28}$

Bireyin sağlığını geliştirmesi için harekete geçme noktasında etkili olan faktörlerden biri de bilgi düzeyidir. Yapılan prospektif bir çalışmada sağlık okuryazarlığını artırmak amacıyla düzenlenen eğitimlerin sağlığın geliştirilmesinde olumlu etkisi olduğu vurgulanmıştır. ${ }^{29}$ Sağlık okuryazarlığ1 düzeyi yüksek olan bireylerin daha az riskli davranışlar sergilediği (düzensiz beslenme, fiziksel aktivite azlığı gibi) belirtilmiştir. ${ }^{23} 18-90$ yaş arasındaki bireylerle yürütülen bir çalışmada sağlık okuryazarlığı düzeyi yüksek olan bireylerin daha fazla sebze-meyve tükettiği bulunmuștur. ${ }^{30}$

Sonuç olarak araştırmamızda katılımcıların büyük çoğunluğunun sağlık okuryazarlığ yetersiz olarak bulunmuştur. Yetersiz seviyede sağlık okuryazarllğıının vücut artışı ile ilişkili olduğu sonucuna varılmıştır.

Sağlık okuryazarlı̆̆ karmaşık bir kavram olup etkileyen çok sayıda faktör bulunmaktadır. Gelecekte yapılacak araştırmalar, sağlık okuryazarlığını etkileyebilecek diğer faktörleri ele alabilir, sağlık okuryazarlı̆̆ına yönelik müdahale çalışmaları ile bireyler ileriye dönük takip edilerek değerlendirilebilir. Düzenli sağlık eğitim programları ile bireylerin ve toplumun sağlıklı bir hayat tarzı benimsemesi sağlanabilir, böylece sağlık okuryazarlığındaki olumlu değişim obezite oranlarını azaltabilir. Beslenme ve fiziksel aktivite eğitimleri, davranışsal terapi, motivasyonel görüşme teknikleri ile bireylerin kilo kaybetmesi sağlanabilir. Sağlık profesyonellerinin, sağlıklı yaşam için bazı davranışların kazandırılmasında bireylerin sağlık okuryazarlığını da dikkate almaları gerekmektedir. Toplumun bu konuda farkındalığının artması sadece kilo problemlerinin çözümünde değil sağlığın geliştirilmesi, kronik hastalıkların yönetimi, hastanelere gereksiz başvuru gibi konularda da olumlu etkiler sağlayabilir.

Furat Üniversitesi Sosyal ve Beşeri Bilimler Araştırmaları Etik Kurulunun 17.10.2019 tarih ve 36/12 Nolu etik kurul kararı ile araştırmamız için izin alınmıştır. 


\section{Kaynaklar}

1. Özdenk GD, Özcebe LH. Bir üniversite çalışanlarının beslenme okuryazarlı̆ı̆, beslenme davranışları ve ilișkili faktörler. Türkiye Halk Sağhlğı Dergisi 2018; 16(3): 178-189.

2. Health Literacy; Health Promotion Glossary, 1998. WHO. https://www.who.int/healthpromotion/health-literacy/en/

3. Dodson S, Good S, Osborn R. Health literacy toolkit for low-and middle income countries: A series of information sheets to empower communities and strengthen health systems. Delhi: World Health Organization, Regional Office for South-East Asia; 2015.

4. Kickbusch I, Wait S, Maag D. Navigating health: The role of health literacy. London: Alliance for Health and the Future, International Longevity Centre-UK; 2006.

5. Berkman ND, Sheridan SL, Donahue KE, Halpern DJ, Crotty K. Low health literacy and health outcomes: an updated systematic review. Ann Intern. Med 201; 155:97-107.

6. Adams RJ, Appleton SL, Hill CL, Dodd M, Findlay C, Wilson DH. Risks associated with low functional health literacy in an Australian population. Med J Aust 2009; 191: 530-534.

7. Wu JR, Moser DK, DeWalt DA, Rayens MK, Dracup K. Health Literacy mediates the relationship between age and health outcomes in patients with heart failure. Circ Heart Fail 2016;9:50

8. Gazmararian JA, Williams MV, Peel J, Baker DW. Health literacy and knowledge of chronic disease. Patient Educ Couns 2003;51: 267-275.

9. Bilir N. Erbaydar Paksoy N. Bulaşıcı olmayan hastaliklar ve kontrolü. In: Güler Ç, Akın L, Editors. Halk Sağlı̆̆ı Temel Bilgiler 3. Ankara: Hacettepe Üniversitesi Yayınlarl;2015.p.1542.

10. Durusu-Tanrı̈ver M. Ylldırım HH. Demiray-Ready FN. Çakır B. Akalın HE. Türkiye săğlk okuryazarlı̆̆ araștırması. Bilimsel Rapor. Sağlı-Sen Yayınları - 25. 1. Baskı: 2014 Aralık.

11. Sezer A. Sağlı okuryazarlı̆̆ının sağlıkl yaşam biçimi davranışları ile ilişkisi. Yüksek Lisans Tezi, Marmara Üniversitesi, İstanbul, 2012.

12. Yllmazel G, Cetinkaya F. Relation between health literacy levels, Hypertension awareness and control among primary-secondary school teachers in Turkey. Aims Public Health 2017;4(4):314-325.

13. Speirs, KE. Health literacy and nutrition behaviors among low-income adults. J Health care for the poor and underserved. 2012;23(3):1082-91.

14. Kennen EM, Davis TC, Huang J, Yu H, Carden D, Bass R, et al. Tipping the scales: The effect of literacy on obese patients' knowledge and readiness to lose weight. Southern Medical Journal 2005;981: 15-18.

15. Okyay P, Abacıgil F. Türkiye sağlık okuryazarlı̆ğ ölçekleri güvenilirlik ve geçerlilik çalışması. Bilimsel Rapor. T.C. Sağlık Bakanlığı Yayın No: 1025. 1. Baskı: Mayıs 2016

16. Ozdemir H, Alper Z, Uncu Y, Bilgel N. Health literacy among adults: A study from Turkey. Health Educ Res 2010;25(3):464-77.

17. Mushi-Brunt C, Haire-Joshu D, Elliott M. Food spending behaviors and perceptions are associated with fruit and vegetable intake among parents and their preadolescent children.J Nutr Educ Behav. 2007;39(1):26-30.
18. Zoellner J. Health literacy is associated with healthy eating index scores and sugar-sweetened beverage intake: findings from the rural Lower Mississippi Delta. J of the Americ Dietetic Associat 2011;111(7):1012-20.

19. Shih SF, Liu CH, Liao LL, Osborne RH. Health literacy and the determinants of obesity: a population-based survey of sixth grade school children in Taiwan. BMC Public Health 2016;22(16):280.

20. Body Mass Indeks, World Health Organization. http://www.euro.who.int/en/health-topics/ disease-prevention/nutrition/a-healthy-lifestyle/body-mass-index-bmi

21. TehraniBanihashemi S, Amirkhani M, Haghdoost A, Alavian S, Asgharifard H, Baradaran $H$, et al. Health Literacy and the Influencing Factors: A Study in Five Provinces of Iran. Strides Dev Med Educ 2007;4(1):1-9.

22. Mohammadi Z, TehraniBanihashemi A, Asgharifard H, Bahramian M, Baradaran HR, Khamseh ME.Health literacy and its influencing factors in Iranian diabetic patients. Med JIslam RepubIran 2015;29:230.

23. LIU, Yong-Bing, et al. Relationship between health literacy, health-related behaviors and health status: A survey of elderly Chinese. International journal of environmental research and public health 2015, 12(8): 9714-9725.

24. Alamari A, Alkwaari M. Assessing the level of health literacy among adult visitors in the primary health care sitting of National Guard Health Affair, Jeddah, Saudi Arabia. J. Fam. Community Med 2010. (sayfa sayisi yok)

25. Sharif I, Blank AE. Relationship between child health literacy and body mass index in overweight children. Patient Education and Counseling 2010;79(1): 43-48.

26. Huizinga MM, Beech BM, Cavanaugh KL, Elasy TA, Rothman RL. Low numeracy skills are associated with higher BMI. Obesity 2008; 168: 1966-68

27. Lassetter JH, Clark L, Morgan SE, Brown LB, VanServellen G, Duncan K, et al. Health literacy and obesity among native Hawaiian and Pacific Islanders in the United States. Public Health Nurs 2015;32(1):15-23.

28. Michou M, Demosthenes BP, Vassiliki C. "Low health literacy and excess body weight: A systematic review." Central European journal of public health 2018; 26(3): 234-241.

29. Taggart J, Williams A, Dennis S, Newall A, Shortus T, Zwar N, Denney-Wilson E, Harris MF. A systematic review of interventions in primary care to improve health literacy for chronic disease behavioral risk factors. BMC Fam Pract 2012:13,

30. Von Wagner C, Knight K, Steptoe A, Wardle J. Functional health literacy and health-promoting behavior in a national sample of British adults. J. Epidemiol. Community Health 2007; 61, 1086-1090. 